\title{
Private facilities must make educational contribution
}

$\mathrm{T}$ he scope and quality of residency training in Canada may ultimately be compromised unless privately operated medical facilities become integral players in the education of future physicians, says the Royal College of Physicians and Surgeons of Canada.

With ongoing devolution of care, particularly specialized procedures, to private facilities, it will be increasingly difficult to expose residents to the "full breadth of their discipline" at traditional centres like public hospitals, the College states in a July policy statement, Safeguarding the Quality of the Educational Continuum and Medical Workforce in Canada's Complex Health Care System, (rcpsc.medical.org).

But while calling for the development of "formalized relationships" between private facilities and public hospitals, as well as faculties of medicine, the Royal College argues that private facilities must be prepared to elevate their own bars as a contribution to medical education. Such facilities "must:

- have an appropriate number of practitioners with faculty appointments;

- fulfill requirements for education rotations as required by the faculties of medicine and the Royal College's standards of accreditation; and

- be encouraged and supported to fulfill their potential to conduct quality research, whether basic, clinical translational, outcomes-related or other."

Royal College President Dr. William Fitzgerald says a move to include private facilities in medical training is integral to ensuring quality education and patient care, as well as a long-term supply of physicians. "The growing complexity of health care, pressures to reduce wait times and increased presence of private clinics has provided a new landscape for the delivery of health care and medical education and training."

Fitzgerald adds that the Royal College's statement isn't a foray into the perpetual debate over public and private medicine but, rather, a comment on "the coresponsibility of ensuring quality residency training."

The College's 8-page statement

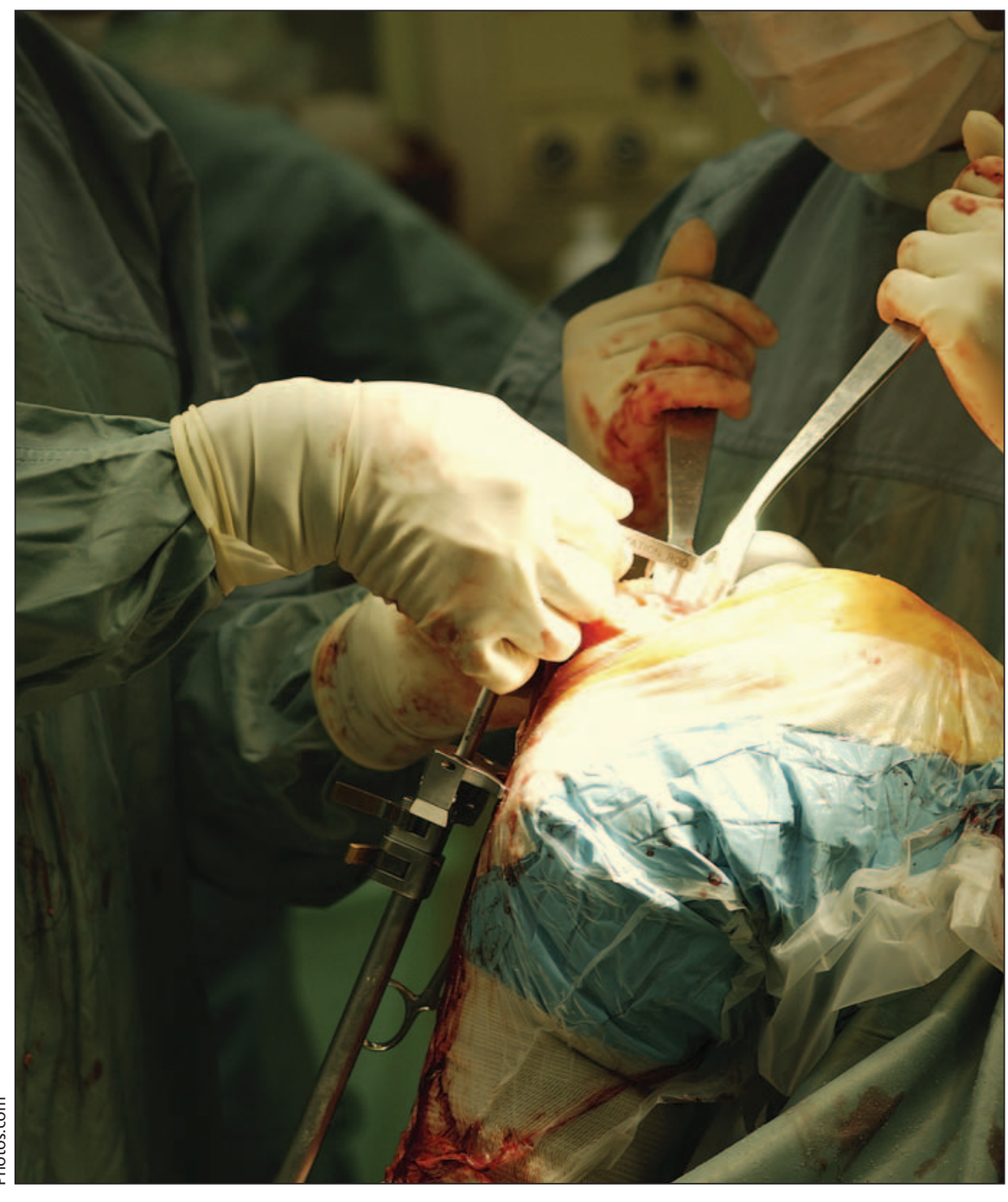

With the ever-increasing number of privately run facilities, the college is concerned that residents trained exclusively in the public system may lose exposure to procedures that are now primarily being performed by private clinics.

stresses that such coresponsbility is vital to ensuring "an optimal educational experience. It has been observed in various jurisdictions that private centres tend to perform relatively straightforward, high-volume elective cases, leaving public hospitals to deal with an increasing number of complex and high-risk patients. This leads to the concern that residents training solely in the traditional public centres are being deprived of the experiences that have been devolved to private clinics."

The report argues that, whether operating in the public or private systems, the entire medical profession "has a collective responsibility to advocate for timely access to the highest standards of care for all patients and to educate future physicians."

Fitzgerald says that, from the College's perspective, the key will be ensure that the quality of specialty education isn't compromised. "The college will certainly be monitoring residents' training programs in the regular accreditation cycles so that as more and more training devolves, perhaps to the private sector, that sector will certainly have to demonstrate that tenets of good professional education are being maintained." - Erin Driscoll, CMAJ

DOI:10.1503/cmaj.081673 